\title{
Alpha-radioactivity-related upper age limit for thermoluminescence dating?
}

\author{
K S V NAMBI \\ Health Physics Division, Bhabha Atomic Research Centre, Trombay, Bombay 400085, India
}

MS received 30 November 1982; revised 20 November 1983

\begin{abstract}
A systematic underestimation of the age of mineralisation by the thermoluminescence ( $\mathrm{TL}$ ) technique has been observed in a variety of samples older than Quaternary although their natural TL was not saturated. The samples included calcites, oozes, lime stones, shales, gypsum, basalts and dolerites. It is shown that the rL build-up in nature reaches a dynamic equilibrium level much ahead of the lifetime of the TL trap concerned and is solely determined by the alpha radioactivity of the sample; the validity for TL dating does not exist once such an equilibrium is reached. For the samples considered, the limiting Paleo-alpha dose for TL dating validity works out to be about 150 kilorads; beyond this dose, the TL age and the geological age bears a ratio given by $t^{\prime} / t=a\left[\int_{0}^{t} \dot{D}_{\alpha} \mathrm{d} t\right]^{-b}$ where $a$ and $b$ are constants and $\dot{D}_{\alpha}$ is the annual alpha irradiation rate in the sample. For a suite of samples with $b \neq 1$, relative dating seems possible by the TL technique. It may be generalised that samples with $1 \mathrm{ppm}$ level of $U$, Th content cannot be TL dated if they are older than about 500 kiloyears even though their NTL trap lifetimes may be 100 myrs; conversely, a 1000 myr-old sample can be TL dated only if its $\mathrm{U}$, Th content is much less than ppb levels and its TL trap lifetime greater than $10^{10}$ years.
\end{abstract}

Keywords. Thermoluminescence dating; Paleoalpha dose; geology; trap lifetime; calcite; basalts; shales; dolerites; gypsum.

\section{Introduction}

The potential of thermoluminescence (TL) in dating applications was first visualised by geologists and their success was mostly limited to relative dating (McDougall 1968). Geological applications however receded to the background during late sixties and the seventies because of reasonable successes that could be readily realised in archaeological dating applications (See for example, the Proceedings of the Specialist Seminars on TL dating, 1978, 1980 and 1982). Improved understanding in thermoluminescent dosimetry problems and development of sensitive instruments contributed in good measure to this success story whose real basis however rested on the fact that the "start of the TL clock" could be well defined in archaeology namely, the firing of the pottery in ancient times and the uncertainties affecting the TL during the relatively small archaeological periods could be neglected or easily taken care of. Recently more reports have appeared extending the datable periods to the Quaternary. We seem to be entering back into geology and it is being pondered at this stage as to how far back we will be able to date with the aid of $\mathrm{TL}$ technique.

\section{The well-known factors which dictate the upper limit in TL dating}

The easily conceivable factors which will set the upper limit in any TL dating attempt are: (i) the lifetime of the trap giving rise to the naturally accumulated thermolumi- 
nescence (NTL); and, (ii) the onset of saturation of TL build-up in nature. The fundamental basis in $\mathrm{TL}$ dating concerns continuous self-irradiation (due to radioactive impurities in the material-mostly $\mathrm{U}, \mathrm{Th}$ and $\mathrm{K}$-plus a small contribution due to cosmic rays) at a constant dose rate of $\dot{D}$ rady $^{-1}$ during the entire past and evaluation of the total accumulated radiation dose-Paleodose, PD-through the rL emitted by the sample. Thus the geologic age ( $\mathrm{t}$ yrs) is given by,

$$
(\text { PD) }=\dot{D} \cdot t \text {. }
$$

In reality, since the alpha irradiation contributes to less TL than beta, gamma and cosmic irradiations on per rad basis (the latter three types of radiations possess the same $\mathrm{TL}$-induction efficiency) the equation should be written more correctly as,

$$
(\mathrm{PDE})_{\gamma}=\dot{D}_{\mathrm{eq}} \cdot t \text {, }
$$

where $(\mathrm{PDE})_{\gamma}=$ Paleodose equivalent in gamma rads and,

$$
\dot{D}_{\mathrm{eq}}=k \cdot \dot{D}_{\alpha}+\dot{D}_{\beta}+\dot{D}_{\gamma}+\dot{D}_{c},
$$

$k$ being the relative TL-induction efficiency of alpha radiation as compared to beta, gamma or cosmic radiations. If the lifetime of the trap at ambient storage temperature $T^{\circ} \mathrm{K}$ is denoted by $\tau$ years $\left[\tau=s^{-1} \exp (E / k T)\right.$ where $s$ is the frequency factor and $E$ is the thermal activation energy associated with the trap], the continuous dose build-up taking into account the ever-present thermal decay can be given by,

$$
(\mathrm{PDE})_{y}=\dot{D}_{\mathrm{eq}}[1-\exp (t / \tau)] \cdot \tau
$$

For $t \ll \tau$ i.e. when the geologic age to be determined is much less than the trap life time, (3) reduces to (2) establishing validity for TL dating. If however, the geologic age is much greater than the lifetime of the trap, (3) reduces to

$$
(\text { PDE })_{\text {equil }}=\dot{D}_{\text {eq }} \cdot \tau
$$

pointing to attainment of dynamic equilibrium and the paleodose evaluated will be independent of the geologic age; if the dose $D_{s}$ at which the TL output of the sample reaches saturation is less than $\dot{D}_{\mathrm{eq}} \cdot \tau$, then the paleodose evaluated will be $D_{s}$ itself. Thus,

$$
(\mathrm{PDE})_{\mathrm{equil}}=\dot{D}_{\mathrm{eq}} \tau \text { or } D_{s}
$$

and under both the conditions validity for TL dating does not exist. It is apparent from the foregoing discussion that the upper limit for TL dating of a sample from the traditionally known factors is roughly $\tau / 10$ (when $t=\tau / 10 \mathrm{TL}$ dating will underestimate by about $5 \%$-see figure 3 ) or $D_{s} / \dot{D}_{\text {eq }}$ whichever is less.

\section{Non-linear build-up of NTL and the basis of relative dating - a critical reappraisal}

It has been well recognised since early attempts that high LET radiations-alpha is of particular interest to our present discussions - produce also new TL traps besides filling up some existing ones. (Each incident alpha particle of $5 \mathrm{MeV}$ energy-typically found in $U$, Th radioactive series-can produce up to 200 displacements in a material of $\mathrm{Z} \simeq 30$ as compared to the requirement of an irradiation with nearly 2000 gamma photons of about the same energy to produce a single displacement). Thus Zeller and 
Ronca (1963) have argued that the NTL build-up is not at all linear at a constant rate but somewhat supralinear asymptotically approaching a saturation value; in such a case it can be expected that the present-day laboratory calibration of the NTL in terms of the PDE will lead to gross underestimation. Based on TL measurements on limestones of known ages they hypothesised that the ratio of PDE to the alpha radioactivity of the sample-called the "TL index"-will be indicative of the relative ages when a group of genetically related samples with the same mineralogy are considered. (Zeller and Ronca did not use the term PDE as such which is a currently accepted apt term; nevertheless they implied the same in their definition of 'TL index'). They showed that the TL index $v s$ alpha radioactivity plot resulted in parallel isochron lines with a negative slope the farthest line from the origin covering the oldest samples (see e.g. figure 6.16 in Hutchison 1968). This hypothesis seemed to have yielded satisfactory fitting with the known stratigraphic ages on a relative scale even up to about 400 million years. It is however very difficult to comprehend the successful relative dating results on samples as old as a few hundred million years when the concerned trap life time itself is only 100 myrs or less [Typically in $\mathrm{CaCO}_{3}$ lattice, the $280^{\circ} \mathrm{C}$ peak has been reported to exhibit a lifetime of $10^{8}$ years (Wintle 1977; Nambi and Mitra 1978)]. It is also difficult to believe that the TL sensitivity should have changed (due to the alpha-induced new traps) over such a magnitude. In this connection it is worth recalling Medlin's (1968) observations on the alpha-induced TL trap production in $\mathrm{CaCO}_{3}$ lattice: (i) The alpha-induced production of traps is somehow dictated by the impurities and lattice defects initially present. The maximum number of possible sites at which the alpha-induced NTL traps can be produced is fixed; this is invariably of the same order of magnitude as the traps originally present. (corrollary: the PDE underestimation can be only within an order of magnitude). (ii) the trap-producing rate-constant will be much smaller than the trapfilling rate-constant; and, (iii) the trap production may be reasonably expected to reach completion in periods of the order of million years. Attempts to verify the increased TL sensitivity of a sample after a sufficient laboratory alpha irradiation (equivalent to the integrated exposure in Nature over geological periods) have however not yielded any positive support. (To take into account the third criterion of Medlin cited above, experiments were done on Quaternary samples with very low levels of inherent alpha radioactivity).

\section{Paleo alpha dose and TL underestimation of the age of mineralisation}

As all the earlier-reported data in literature suffer from the drawback of nonstandard procedure for the evaluation of the paleodose equivalents and almost total neglect of all the various components of the self-irradiation rates, an analysis of the underestimations of the geological ages by the $T L$ technique was restricted to the data obtained in this laboratory. The samples comprised calcites, limestones, kankar, oozes, gypsum, dolerites, basalts and shales; the known geological ages (paleontological or K/Ar) ranged between Quaternary and Precambrian (table 3). The mineral responsible for the TL in each of these samples is calcite, gypsum or plagioclasse as the case may be. The NTL trap lifetimes for the respective storage temperatures (table 1) are sufficiently greater than the geological ages of the samples concerned excepting for nos. 7 to 12 in table 3 . These are included as the samples have yielded TL ages even much less than the trap lifetimes. The (PDE) $y$ values of the samples (table 2) are all below saturation which is 
Table 1. TL stability in various geological samples

\begin{tabular}{|c|c|c|c|c|}
\hline $\begin{array}{l}\text { Geological } \\
\text { sample }\end{array}$ & $\begin{array}{l}\text { Main host lattice/ } \\
\text { mineral responsible }\end{array}$ & $\begin{array}{l}\text { NTL } \\
\text { peak }\end{array}$ & $\begin{array}{c}\text { Estimated } \\
\text { NTL trap } \\
\text { lifetime } \\
\tau \text { yrs at } \\
\text { indicated } \\
\text { storage temp* }\end{array}$ & References \\
\hline Limestone & & $330^{\circ} \mathrm{C}$ & 3 myrs $\left(25^{\circ} \mathrm{C}\right)$ & $\begin{array}{l}\text { Nambi \& } \\
\text { Mitra, } 1978\end{array}$ \\
\hline Kankar & & $330^{\circ} \mathrm{C}$ & 3 myrs $\left(25^{\circ} \mathrm{C}\right)$ & Wintle 1977 \\
\hline Deep sea oozes & $\mathrm{CaCO}_{3}$, calcite & $330^{\circ} \mathrm{C}$ & $>10^{8}$ myrs $\left(10^{\circ} \mathrm{C}\right)$ & \\
\hline Marine shales & & $275^{\circ} \mathrm{C}$ & $10^{8}$ yrs $\left(10^{\circ} \mathrm{C}\right)$ & \\
\hline Marine gypsum & $\mathrm{CaSO}_{4}$ & $350^{\circ} \mathrm{C}$ & $10^{12}$ yrs $\left(25^{\circ} \mathrm{C}\right)$ & Nambi 1982 \\
\hline $\left.\begin{array}{l}\text { Basalt } \\
\text { Dolerite }\end{array}\right\}$ & Plagioclasse & $370^{\circ} \mathrm{C}$ & $\begin{array}{r}10^{8}-10^{10} \mathrm{yrs} \\
\left(25^{\circ} \mathrm{C}\right)\end{array}$ & $\begin{array}{l}\text { Durrani et al } \\
1976\end{array}$ \\
\hline
\end{tabular}

* $\tau$ values hardly change by about $10 \%$ if the order of kinetics changes from 1 to 2 (Chen 1969).

Table 2. Natural radioactivity data and the estimated (PDE), values for various geological samples

\begin{tabular}{rlrrrr}
\hline $\begin{array}{l}\text { Sl. } \\
\text { No. }\end{array}$ & Sample code & K\% & $\begin{array}{c}\text { Gross alpha } \\
\text { activity } \\
\text { cph** }\end{array}$ & $k$ factor & (PDE) ${ }^{* *}$ rads : \\
\hline 1 & MCG & 0.003 & 12.05 & 0.34 & 3255 \\
2 & DK & 0.400 & 0.65 & 0.07 & 4788 \\
3 & MG & 0.004 & 2.05 & 0.21 & $7.35 \times 10^{4}$ \\
4 & 219/2/2 & 0.060 & 30.00 & 0.10 & $1.57 \times 10^{4}$ \\
5 & 219/9/2 & 0.300 & 18.10 & 0.10 & $5.17 \times 10^{4}$ \\
6 & TW2 & 1.734 & 48.60 & 0.10 & $3.5 \times 10^{4}$ \\
7 & TW10 & 1.370 & 43.80 & 0.12 & $2.5 \times 10^{4}$ \\
8 & TW11 & 0.502 & 34.50 & 0.24 & $5.5 \times 10^{4}$ \\
9 & TW18 & 0.044 & 9.90 & 0.10 & $1.6 \times 10^{4}$ \\
10 & S & 0.000 & 0.66 & 0.50 & $9 \times 10^{4}$ \\
11 & P14 & 1.050 & 11.20 & 0.51 & $9.4 \times 10^{4}$ \\
12 & BCR 1 & 1.700 & 27.80 & 0.10 & $4 \times 10^{4}$ \\
\hline
\end{tabular}

** from thick sample of $13.86 \mathrm{~cm}^{2}$; Background of the counter is $0.160 \pm 0.065 \mathrm{cph}$

estimated to set in at about 350 kilorads; strict linearity can be assumed typically to about 70 kilorads (figure 1). For samples with (PDE) values above this dose, saturation correction assuming an exponential build-up is done (Nambi 1980). From table 3, it is seen that excepting for the recent (archaeologically important) samples of kankar and burnt limestone, the TL ages are grossly underestimated, sometimes by four orders of magnitude. Even for serial nos. 7 to 12 where underestimation was expected because of the shorter trap lifetime, the underestimation factor ( = TL age/geol. age) does not seem to be by $\tau / t$, but much less. A plot of the $\mathrm{TL}$ ages against the respective geological ages 
Table 3. TL dating results on a variety of geological samples

\begin{tabular}{|c|c|c|c|c|c|c|c|}
\hline $\begin{array}{l}\text { S1. } \\
\text { No. }\end{array}$ & Sample & Code & $\begin{array}{l}\text { TL age } \\
\text { obtained } \\
\text { myrs }\end{array}$ & $\begin{array}{l}\text { Geol. age* } \\
\text { myrs }\end{array}$ & $\begin{array}{c}\text { Paleo Alpha } \\
\text { dose } \\
\text { rads }\end{array}$ & $\begin{array}{c}\text { TL age/Geol. } \\
\text { age. }\end{array}$ & Reference \\
\hline 1. & $\begin{array}{l}\text { Burnt } \\
\text { Limestone } \\
\text { (ancient cave) }\end{array}$ & MCG & 0.0174 & 0.020 & $7.5 \times 10^{3}$ & 1.0 & $\begin{array}{l}\text { Nambi and } \\
\text { Murthy } \\
\text { (1981) }\end{array}$ \\
\hline 2. & Kankar & DK & 0.0229 & 0.02245 & $4.7 \times 10^{2}$ & 1.0 & $\begin{array}{l}\text { Nambi and } \\
\text { Hegde (1982) }\end{array}$ \\
\hline 3. & $\begin{array}{l}\text { Marine } \\
\text { (Gypsum } \\
\text { Mediteranean) }\end{array}$ & MG & 1.96 & $3 \sim 6$ & $2.9 \times 10^{5}$ & 0.5 & Nambi (1980) \\
\hline 4. ? & $\mathrm{CaCO}_{3}$ oozes & $219 / 2 / 2$ & 0.075 & 1 & $9.4 \times 10^{5}$ & $\left.7.7 \times 10^{-2}\right\}$ & Nambi et al \\
\hline 5. $\}$ & $\begin{array}{l}\text { (Indian Ocean } \\
\text { bed) }\end{array}$ & $219 / 9 / 2$ & $0-17$ & 5 & $2.9 \times 10^{6}$ & $\left.3.4 \times 10^{-2}\right\}$ & $(1982)$ \\
\hline 6.$)$ & Marine shales & TW2 & 0.065 & $7 \cdot 5$ & $1.2 \times 10^{7}$ & $8.7 \times 10^{-3}$ & \\
\hline 7. & $\begin{array}{l}\text { (Arabian } \\
\text { sea bed) }\end{array}$ & TW10 & 0.054 & $20 \cdot 2$ & $2.9 \times 10^{7}$ & $2.6 \times 10^{-3}$ & $\begin{array}{l}\text { Sadasivan et al } \\
\text { (1981) }\end{array}$ \\
\hline 8. & & TW11 & 0.12 & $24 \cdot 8$ & $2.7 \times 10^{7}$ & $4.8 \times 10^{-3}$ & \\
\hline 9. ) & & TW18 & $0-23$ & 43.5 & $1.4 \times 10^{7}$ & $\left.5.3 \times 10^{-3}\right)$ & \\
\hline 10. & Calcite & $\mathbf{S}$ & $3 \cdot 29$ & 1700 & $3.5 \times 10^{7}$ & $1.9 \times 10^{-3}$ & $\begin{array}{l}\text { Nambi and Mitra } \\
(1978)\end{array}$ \\
\hline 11. & Dolerite & P14 & 0.27 & 900 & $3.6 \times 10^{8}$ & $3.0 \times 10^{-4}$ & $\begin{array}{l}\text { Nambi and } \\
\text { Sankaran } \\
(1982)\end{array}$ \\
\hline 12. & Basalt & $\begin{array}{l}\text { USGS } \\
\text { BCRI }\end{array}$ & 0.114 & 25 & $2.5 \times 10^{7}$ & $4.6 \times 10^{-3}$ & $\begin{array}{l}\text { Nambi et al } \\
(1978)\end{array}$ \\
\hline 13. ) & $\begin{array}{l}\text { Hawaiian } \\
\text { Basalt }\end{array}$ & Molle & 0.225 & 1.35 & $6.4 \times 10^{5}$ & $0 \cdot 167$ & \\
\hline 14. & & $5 \times 340$ & 0.300 & $3 \cdot 30$ & $1.3 \times 10^{6}$ & $9.0 \times 10^{-2}$ & \\
\hline 15. & & H 71-10 & $0-066$ & 0.062 & $7 \cdot 8 \times 10^{4}$ & 1.0 & Derived from \\
\hline 16. & & 035 & 0.150 & 0.14 & $1.2 \times 10^{5}$ & $1 \cdot 0$ & May 1977 \\
\hline 17. & & H II-3 & $0 \cdot 14$ & 0.15 & $1.0 \times 10^{5}$ & 1.0 & \\
\hline 18. & & 042 & 0.182 & 0.184 & $1.6 \times 10^{5}$ & $1 \cdot 0$ & \\
\hline
\end{tabular}

* Shales and oozes - paleontological; basalts \& dolerites - K/Ar dates; kankar \& burnt limestone $-{ }^{14} \mathrm{C}$ dates

has been presented in figure 2 and any definite relationship between the two is not obvious from this plot. From figure 3 it is seen that the samples have 'behaved' as if their NTL trap lifetime was only $10^{5}$ years against $10^{8}$ years estimated in the laboratory. It is also worth recalling here that TL kinetics, whether first or second order, cannot result in more than a $10 \%$ change in the trap lifetimes (Chen 1969).

Working on Zeller's hypothesis, it was attempted to see if the continuous low level alpha self-irradiation had any influence on the TL underestimation of the age. In figure 4 is presented a plot between the underestimation factor $\left(t^{\prime} / t\right)$ and the Paleoalpha dose received $\left(D_{\alpha t}=\int_{0}^{t} \dot{D}_{\alpha} \cdot \mathrm{d} t\right)$ by the respective samples. It would seem from this graph that there exists a limit for the Paleoalpha dose ( 150 kilorads approximately) beyond which TL dating always leads to underestimation strictly in proportion to the paleoalpha dose 

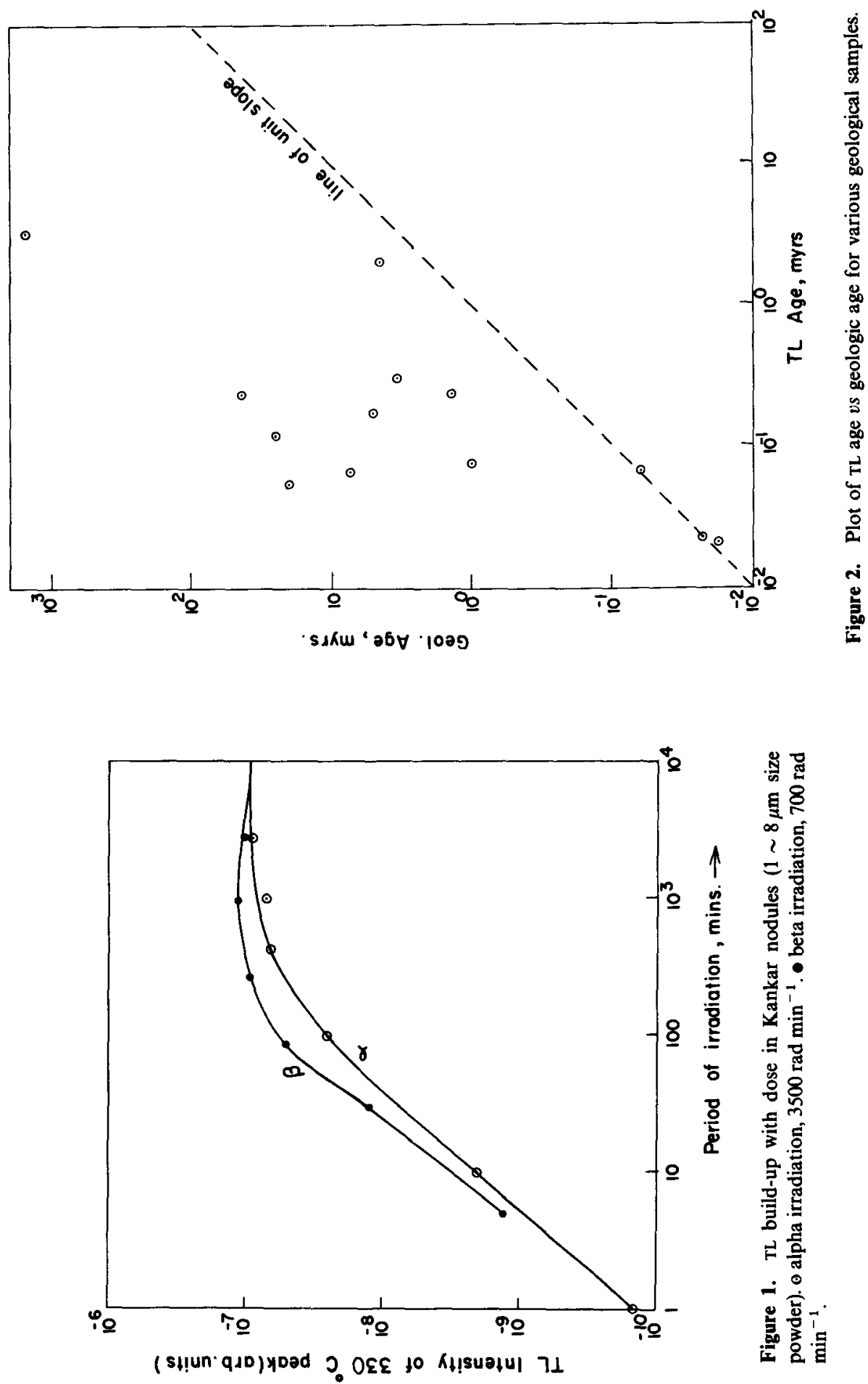

胥

용

$\infty$

$1 \stackrel{2}{=}$

$-{ }^{m} \underline{0}$

.

- उु

음 늠

‥

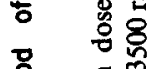

\&

是覀

อ.

보을

$+\stackrel{2}{\circ}$

离范 


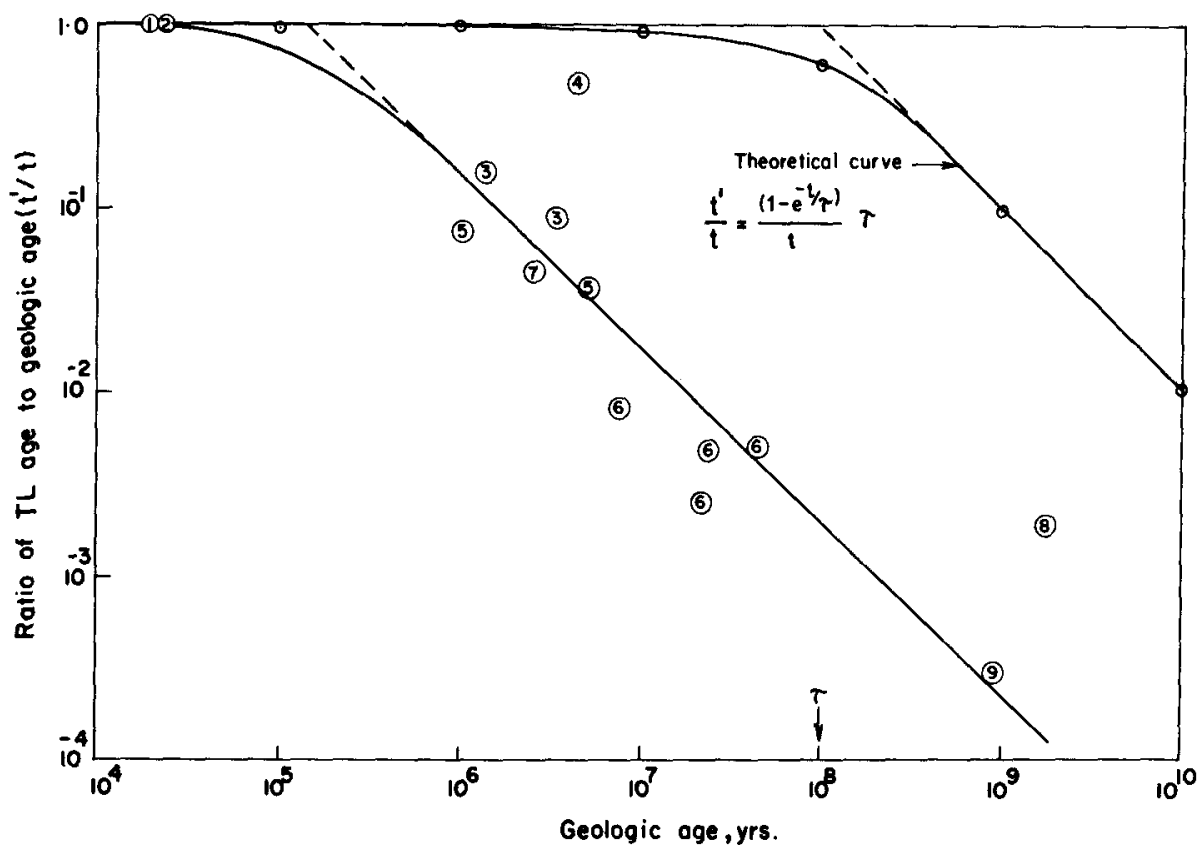

Figure 3. Comparison of theoretical and experimental curves for the deviations of TL age estimate from the true geological ages for samples with a NTL trap lifetime of 100 myrs. (1) kankar. (2) limestone. (3) Hawaiian basalt. (4) marine gypsum. (5) carbonate oozes. (6) shales. (7) USGS basalt, BCR-I. (8) calcite. (9) dolerites.

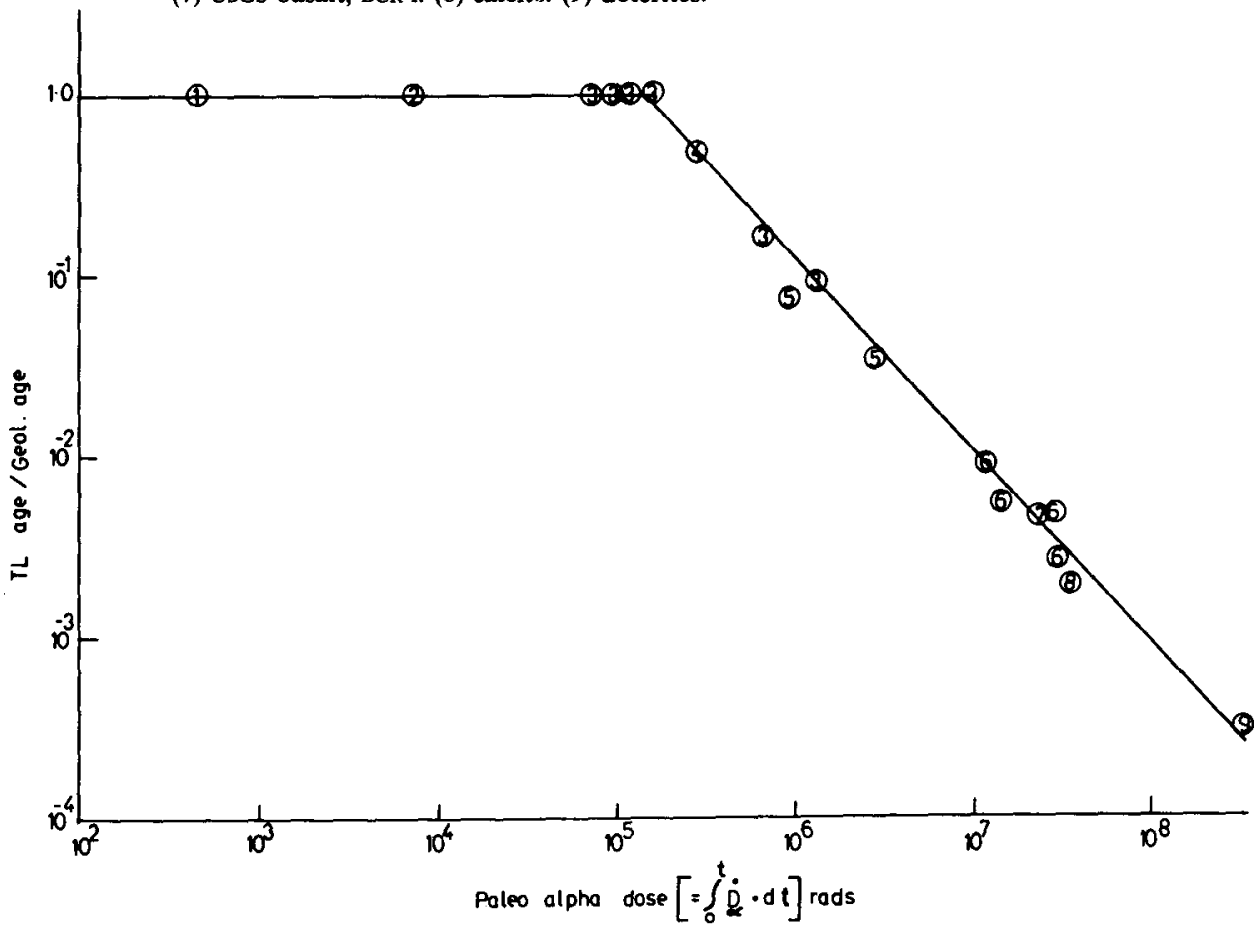

Figure 4. Deviation of TL age from the true geological ages with progressive increase of Paleoalpha dose of the sample (details of samples same as in figure 3 ). 


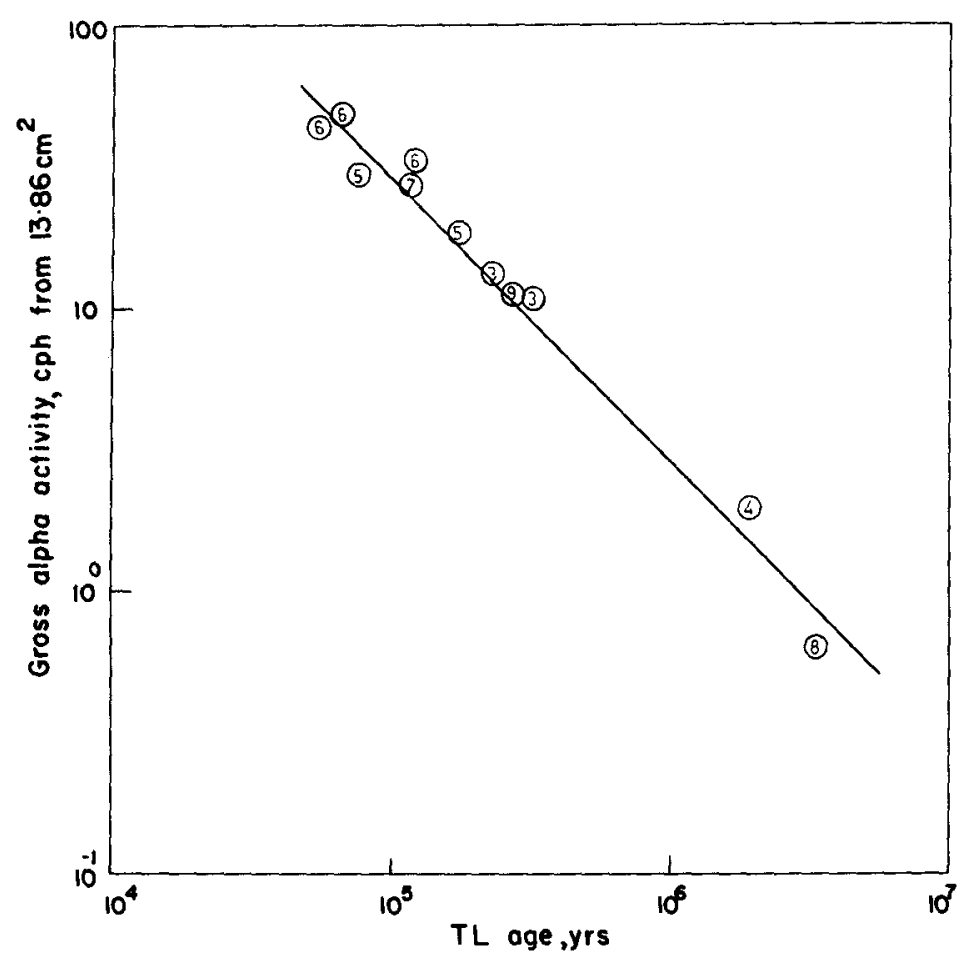

Figure 5. Relation between TL age and gross alpha activity for geological samples where TL dating technique failed to yield the true geological ages. (Details of samples same as in figure 3).

on a log-log plot. It is also interesting to find that the $\mathrm{TL}$ dates and the alpha activities of Hawaiian basalts reported by May (1977) fit nicely in figure 3: all samples TL dated successfully by him (as corroborated by $\mathrm{K} / \mathrm{Ar}$ dates) plot exactly below the predicted paleoalpha dose limit and the two oldest samples which could not be TL-dated successfully fall on the same underestimation line predicted here.

The general equation satisfying the TL underestimation portion of figure 4 can be written as

$$
t^{\prime} / t=a\left(D_{\alpha, t}\right)^{-b} \text { where } a \text { and } b \text { are constants. }
$$

Case 1 When $b=1$

$$
\begin{aligned}
& t^{\prime}=a / \dot{D}_{\alpha} \text { since } D_{\alpha, t}=\int_{0}^{t} \dot{D}_{\alpha} \cdot \mathrm{d} t=\dot{D}_{\alpha} \cdot t, \\
& \text { or } \quad t^{\prime} \propto 1 / C_{\alpha} \text { as shown in figure } 5,
\end{aligned}
$$

[where $C_{a}$ is the alpha count rate of the sample].

It also follows that $(\mathrm{PDE})_{y}=a\left(\dot{D}_{\mathrm{eq}} / \dot{D}_{\alpha}\right)$.

Case 2 When $b \neq 1$

$$
t^{\prime}=a \cdot t^{1-b} /\left(\dot{D}_{a}\right)^{b}
$$


or

$$
(\mathrm{PDE})_{\gamma}=a \cdot t^{1-b}\left[\dot{D}_{\mathrm{eq}} /\left(\dot{D}_{\alpha}\right)^{b}\right]
$$

In either case it is seen that TL-dating validity does not exist; however it is interesting to realise that in the second case when $b \neq 1$, atleast relative dating can be done: from a suite of samples of known ages, $t^{\prime} / t$ vs $D_{\alpha, t} \log$-log plot can be made and slope $b$ evaluated; then a calibration line of $t^{\prime} \dot{D}_{\alpha}^{b} v s t$ can be made on a log-log scale and the age of any unknown sample from the same suite can be read out.

Another interesting feature to note is the way (PDE) $y$ values acquire a dynamic equilibrium level depending on the $\dot{D}_{\text {eq }} / \dot{D}_{\alpha}$ dose rate ratio. Thus, it can be stated that while the alpha dose rate causes primarily the underestimation of the age, the actual dynamic equilibrium level reached depends upon the $\beta, \gamma$ dose rates and the alpha to $\beta, \gamma$ $T L$ induction efficiency ratio ( $k$-factor).

A physical picture however is lacking at the moment. Considering that the data collected in the present study cover a wide range of values regarding alpha radioactivity, potassium content, $k$ factor and the mineralisation ages, the kind of relationship seen between the TL age underestimation and the alpha radioactivity, cannot be ignored as accidental. More careful observations are however needed to put the empirical relationship $t^{\prime} / t=a D_{\alpha, t}^{-b}$ on a firm basis.

The closest similarity which the author has come across in literature is on ESR dating of quartz samples of different mineralisation ages (4 to 150 myrs) with varying amounts of alpha radioactivity (Moiseev and Rakov 1977, 1978), the growth of $E_{1}^{\prime}$ centres by natural alpha self-irradiation proceeds linearly with time only as long as the value of $t \cdot \sqrt{C_{u}} \ll 1.4 \times 10^{7}$ where $t$ is the mineralisation age in years and $C_{u}$ is the uranium concentration weight percent; while the surface layers of quartz grains attain equilibrium by the alpha irradiation, there is still slow growth of this centres in the deeper layers by the action of $\beta, \gamma$ radiations: In terms of a Paleoalpha dose in quartz this limit works out nearly to $10^{10}$ rads; this is orders of magnitude higher than the 150 kilorads arrived for TL dating limit in calcite, gypsum and plagioclasse minerals in the present study. It is to be emphasised that the Paleoalpha dose limits envisaged for TL dating should be different for different lattices on account of (i) differences in mass stopping powers for alpha radiation and (ii) differences in thermal annealing characteristics of "alpha tracks" in various lattices. Correlation studies between TL and track etching studies on samples of different ages and with different amounts of radioactivities, may provide very interesting and crucial clues.

\section{Conclusions}

A careful analysis of the scattered data available on TL dating failures in a variety of samples, has led to a possible relationship between the actual Paleoalpha dose received by the sample and the extent by which thermoluminescence underestimates its age. In samples such as calcites, limestones, oozes, gypsum, basalts, shales and dolerites, it seems that about 150 kilorads is the limiting Paleoalpha dose beyond which rL cannot lead to a correct age estimate. The trend predicted $v i z \mathrm{TL}$ age/geol. age $=a\left[\int_{0}^{t} \dot{D}_{\alpha} \mathrm{d} t\right]^{-b}$, can however be proved only when more experimental data on very old samples with negligible $U$, Th content are available. 


\section{References}

Bell W T 1977 Archaeometry 1999

Chen R 1969 J. Electrochem. Soc. 1161254

Hutchison C S 1968 in Thermoluminescence of geological materials (ed.) D J McDougall (London: Academic Press) p. 341

Durrani S A, Khazal K A R and Ali A 1976 Proc. Seventh Lunar Sci. Conf. (New York: Pergamon Press) p. 1157

May R J 1977 J. Geophys. Res. 823023

McDougall D J (ed.) 1968 Thermoluminescence of geological materials (London: Academic Press) p. 678

Medlin W L 1968 Thermoluminescence of geological materials (London: Academic Press) p. 91

Moiseev B M and Rakov L T 1977 Dokl. Akad Nauk. SSR 233679

Moiseev B M and Rakov L T 1978 Dokl. Akad Nauk. SSR 240942

Nambi K S V and Mitra S 1978 N. Jb. Miner. Abh. 133210

Nambi K S V, Bhasin B D and Bapat V N 1978 Thermochim. Acta 25126

Nambi K S V 1980 Proc. Second Specialist Seminar on TL Dating held at Oxford [1982 PACT J. (Strausberg) $6314]$

Nambi K S V and Murthy M L K 1981 Curr. Sci. 50945

Nambi K S V and Hegde K T M 1982 in Natural radiation environment (eds) K G Vohra et al (Delhi: WileyEastern) p. 664

Nambi K S V and Sankaran A V 1982 Proc.Third Specialist Seminar onTL and ESR Dating held at Helsinger Denmark [1983 PACT J. (Strausberg) 9 453]

Nambi K S V, Bapat V N and Sunta C M 1982 (to be published)

Proceedings of First Specialist Seminar on TL dating, Oxford 1978 PACT J. (Strausberg) 2 \& 3

Proceeding of Second Specialists Seminar on TL Dating, Oxford 1980 (1982 PACT J. Strausberg 6)

Proceedings of Third Specialist Seminar on TL and ESR dating, Helsinger, Denmark 19821983 PACT J. (Strausberg) 9

Sadasivan S, Nambi K S V and Murali A V 1981 Mod. Geol. 813

Wintle A G 1977 J. Electrochem. Soc. 3281

Zeller E J and Ronca L B 1963 in Radioactive Dating (Vienna; IAEA) p. 73 